\title{
Comparison of adjuvant FOLFOX4 chemotherapy and oral UFUR/LV following adjuvant FOLFOX4 chemotherapy in patients with stage III colon cancer subsequent to radical resection
}

\author{
MING-YII HUANG ${ }^{1-4}$, CHUN-MING HUANG ${ }^{1,2,5}$, HSIANG-LIN TSAI ${ }^{6,7}$, CHING-WEN HUANG $^{5,7}$, \\ HUI-MIN HSIEH ${ }^{8}$, YUNG-SUNG YEH ${ }^{7,9}$, JENG-YIH WU ${ }^{10,11}$, WEN-MING WANG ${ }^{10,11}$ and JAW-YUAN WANG ${ }^{2,4,7,12}$ \\ ${ }^{1}$ Department of Radiation Oncology; ${ }^{2}$ Cancer Center, Kaohsiung Medical University Hospital; ${ }^{3}$ Department of Radiation Oncology, \\ Faculty of Medicine, College of Medicine, Kaohsiung Medical University; ${ }^{4}$ Center for Biomarkers and Biotech Drugs; \\ ${ }^{5}$ Graduate Institute of Medicine, College of Medicine; ${ }^{6}$ Division of General Surgery Medicine, Department of Surgery; \\ ${ }^{7}$ Division of Colorectal Surgery, Department of Surgery; ${ }^{8}$ Department of Public Health; ${ }^{9}$ Division of Trauma, \\ Department of Surgery; ${ }^{10}$ Division of Gastroenterology, Department of Internal Medicine; \\ ${ }^{11}$ Department of Internal Medicine, Faculty of Medicine, College of Medicine; ${ }^{12}$ Department of Surgery, \\ Faculty of Medicine, College of Medicine, Kaohsiung Medical University, Kaohsiung 807, Taiwan, R.O.C.
}

Received October 2, 2015; Accepted April 13, 2017

DOI: 10.3892/ol.2017.7073

\begin{abstract}
The present study aimed to demonstrate the potential advantage of oral uracil-tegafur (UFUR)/leucovorin (LV) as the subsequent therapy in patients with stage III colon cancer following adjuvant LV, 5-fluorouracil and oxaliplatin (FOLFOX4) chemotherapy. Of a total 143 patients, 62 patients received only FOLFOX adjuvant chemotherapy (FOLFOX4 biweekly x 12 cycles for 6 months), and 81 patients received FOLFOXU adjuvant treatment (which consisted of FOLFOX4 biweekly x 12 cycles for 6 months followed by oral UFUR/LV for an additional 6 months). The 3-year disease-free survival (DFS) rate of the FOLFOXU group was $74.3 \%$; which was superior to that of the FOLFOX4 group (59.9\%). The average DFS time of the FOLFOXU group was superior to that of the FOLFOX4 group ( $\mathrm{P}=0.003)$. The 5-year overall survival (OS) rate of the FOLFOXU group was $76.9 \%$, which was also superior to that of the FOLFOX4 group (63.8\%). The average OS time of patients in the FOLFOXU group was longer than that of the patients in the FOLFOX4 group (hazard ratio, 0.155; 95\% confidence interval, 0.054-0.450; $\mathrm{P}=0.001)$. In comparison to the FOLFOX regimen, the FOLFOXU regimen achieved a more favorable response and survival time without a significant increase of toxicities in patients with stage III colon cancer as the adjuvant chemotherapy.
\end{abstract}

Correspondence to: Professor Jaw-Yuan Wang, Department of Surgery, Faculty of Medicine, College of Medicine, Kaohsiung Medical University, 100 Tzyou 1st Road, Kaohsiung 807, Taiwan, R.O.C.

E-mail: cy614112@ms14.hinet.net

Key words: FOLFOX4, FOLFOXU, stage III colon cancer, disease-free survival, overall survival

\section{Introduction}

Worldwide, in terms of incidence, colorectal cancer (CRC) is the third most commonly occurring cancer in males (after lung and prostate cancer) and the second most commonly occurring in females (after breast cancer) (1). Annually, $\sim 1.36$ million new cases of CRC are estimated to occur worldwide, accounting for 9.7\% of all cancers (1). Approximately 694,000 CRC-associated mortalities occur worldwide annually, accounting for $8.5 \%$ of all cancer-associated mortalities and making CRC the third most common cause of cancer-associated mortality (1). In total, $75-80 \%$ of patients with colon cancer present with localized diseases (2,3). However, despite curative surgery, patients still have a significant probability of disease relapse and cancer-associated mortality (4). Adjuvant therapy is administered immediately following surgery to target any residual tumor cells and reduce the risk of recurrence (5). Much interest has been generated in the last few decades regarding adjuvant treatment (5-7).

A series of large randomized studies performed by the National Surgical Adjuvant Breast and Bowel Project and the National Cancer Institute sponsored co-operative groups has defined the role of adjuvant chemotherapy in patients with stage III colon cancer (8-12). Encouraged by the initial results from the North Central Cancer Treatment Group, 5-fluorouracil (5-FU)/leucovorin (LV) was shown to increase disease-free survival (DFS) and overall survival (OS) in the confirmatory US Intergroup-0035 study, with mature results showing a $40 \%$ reduction in recurrence and a 33\% reduction in mortality (9). This led to the recommendations from the National Institutes of Health consensus conference for this drug combination to be administered as an adjuvant therapy in patients with stage III colon cancer (12). 5-FU/LV became the standard of care in the US and formed the control arm in numerous studies conducted in the 1990s $(13,14)$. 
In Taiwan, CRC is one of the most common of all malignancies and the third leading cause of cancer-associated mortality (15). The incidence of CRC in Taiwan was 40/100,000 in 2011, and this rate has gradually been approaching those of Western nations in recent decades (15). Stage III colon cancer denotes lymph node involvement (16). Radical surgical resection and anastomosis are the only way to cure stage III colon cancer (17-20), and adjuvant chemotherapy has previously been demonstrated to improve clinical outcomes (8).

Post-operative adjuvant chemotherapy for colon cancer is one of the most important clinical advances in oncology to have been introduced in recent years (21-23). Prior to 2000, 5-FU was the only useful cytotoxic agent in the adjuvant setting for patients with stage III colon cancer (24). Subsequently, treatment with levamisole plus 5-FU, rather than with 5-FU alone, was found to reduce the risk of cancer recurrence among patients with stage III colon cancer by $41 \%(\mathrm{P}<0.0001)$, while the overall mortality rate was reduced by $33 \%(\mathrm{P}=0.006)(5)$. Subsequent to that, a multicenter international study of $\mathrm{LV}$, 5-FU and oxaliplatin (FOLFOX4) in the adjuvant treatment of colon cancer [MOSAIC (NCT00275210)] was completed, wherein the toxic effects and efficacy of 6 months of FOLFOX4 treatment were compared with those of 6 months of a 5-FU/LV regimen without oxaliplatin among 2,246 patients with resected stage II or stage III colon cancer (25). According to the results of this MOSAIC trial, adjuvant FOLFOX4 was demonstrated to prolong OS time for patients with stage III colon cancer compared with patients receiving 5-FU/LV without oxaliplatin (25). Therefore, adding oxaliplatin to a regimen of 5-FU and $\mathrm{LV}$ improved the adjuvant treatment of colon cancer (25). Another study demonstrated that the 6-year OS rate in patients with stage III colon cancer was $72.9 \%$ among patients receiving FOLFOX4 and $68.7 \%$ among patients receiving 5-FU/LV [hazard ratio (HR), 0.80; 95\% confidence interval (CI), 0.65-0.97; $\mathrm{P}=0.023$ ] (26). Since then, FOLFOX4 has become the gold standard adjuvant therapy for patients with stage III colon cancer (26).

In an experimental model, oral uracil-tegafur (UFUR; which consists of tegafur and uracil at a molar ratio of 1:4) plus cisplatin prolonged the survival of murine intraperitoneal implanting colon carcinoma in mice and maintained these mice in a relatively improved condition compared with continuous infusion of 5-FU plus cisplatin (27). In 2000, a randomized comparison of the relative efficacies of 5-FU plus LV and UFUR plus LV in 1,530 evaluable patients indicated that the two regimens have similar toxicity profiles (28). Evidence that UFUR plus oral LV is associated with significant antitumor activity and has a well-tolerated toxicity makes this a logical formulation for the adjuvant treatment of colon cancer (29-31). Since UFUR can be taken orally, patients receiving oral UFUR therapy are not required to stay in hospital for long periods (27). Additionally, an improved quality of life and prolonged survival also highlight the potential clinical usefulness of the UFUR therapy in patients with metastatic colon cancer (32).

In 1998, O'Connell et al (10) reported that there was no significant improvement in patient survival when chemotherapy (either intensive-course 5-FU and LV combined with levamisole, or a standard regimen of 5-FU plus levamisole) was administered for 12 months compared with 6 months. In 2005,
Haller et al (23) assessed the three chemotherapy regimens: Low-dose leucovorin plus 5-FU regimen; high-dose LV plus 5-FU regimen; and low-dose LV plus levamisole plus 5-FU regimen, each administered for 30-32 weeks. The control arm was levamisole plus 5-FU for 1 year. Among the four arms, none were statistically superior in DFS time or OS time (23). The duration of adjuvant chemotherapy is usually 6 months; however, the results of studies were all limited to 5-FU plus LV and levamisole.

Although FOLFOX4 has become established as a standard chemotherapeutic regimen, no relevant information regarding the sequential administration of oral UFUR/LV following FOLFOX4 as an auxiliary subsequent adjuvant treatment for patients with stage III colon cancer has been reported thus far. The goal of the present study was to evaluate the efficacy and safety of oral UFUR/LV following FOLFOX4 chemotherapy as adjuvant therapy for patients with stage III colon cancer.

\section{Materials and methods}

Study population. The present study retrospectively analyzed data between January 2007 and October 2012 for 143 resected patients (median, 64 years; age range, 20-84 years; 81 male and 62 female patients) with stage III colon cancer treated with FOLFOX4 adjuvant chemotherapy plus subsequent oral UFUR/LV (FOLFOXU) or FOLFOX4 adjuvant chemotherapy alone at Kaohsiung Medical University Hospital (Kaohsiung, Taiwan). To exclude cases of FOLFOX regimen failure, inclusion criteria required that patients to show no evidence of recurrence (local recurrence or distant metastasis) within the FOLFOX4 treatment period, as well as an Eastern Cooperative Oncology Group performance status of 0-2 (33). Patients with other malignant diseases in their medical history were also excluded. The clinical characteristics of patients are listed in Table I. The present study was approved by the Institutional Review Board of the Kaohsiung Medical University Hospital.

Chemotherapy regimen. The patients were divided into two groups based on the different chemotherapy regimens (FOLFOX4 or FOLFOXU). The FOLFOX4 regimen comprised oxaliplatin $\left(85 \mathrm{mg} / \mathrm{m}^{2}\right)$ as a 2 -h infusion on day 1 , LV (75-90 $\left.\mathrm{mg} / \mathrm{m}^{2}\right)$ administered as a 2-h infusion on days 1 and 2 , followed by a loading dose of $5-\mathrm{FU}\left(400 \mathrm{mg} / \mathrm{m}^{2}\right)$ intravenous bolus, and then $5-\mathrm{FU}\left(600 \mathrm{mg} / \mathrm{m}^{2}\right)$ administered via ambulatory pump for a period of $22 \mathrm{~h}$ on days 1 and 2 , all of which were repeated every 2 weeks. A total of 62 patients received only FOLFOX4 adjuvant treatment (FOLFOX4, biweekly x 12 cycles for 6 months), and 81 patients received FOLFOXU treatment (FOLFOX4 biweekly x 12 cycles for 6 months followed by oral UFUR/LV for an additional 6 months). Oral UFUR and LV were administered for 6 months at a dose of $400 \mathrm{mg} /$ day for UFUR, and $100 \mathrm{mg} /$ day for LV, respectively. Subsequent to detailed information on potential benefits or disadvantages, the patients provided consent to receive FOLFOXU.

If Common Toxicity Criteria (34) grade 3 stomatitis, diarrhea or dermatitis occurred, the dose of oxaliplatin was reduced by $25 \%$. The same reduction was made for grades 3 and 4 neutropenia and in the case of persistent ( $>14$ days) paresthesia, temporary (7-14 days) painful paresthesia or functional 
Table I. The clinicopathological features of the FOLFOX4 group and the FOLFOXU group patients.

\begin{tabular}{|c|c|c|c|c|}
\hline Feature & Overall, $\mathrm{n}$ & FOLFOX4, n (\%) & FOLFOXU, n (\%) & P-value \\
\hline Total & 143 & 62 & 81 & \\
\hline \multicolumn{5}{|l|}{ Sex } \\
\hline Male & 81 & $36(58.1)$ & $45(55.6)$ & \multirow[t]{2}{*}{0.764} \\
\hline Female & 62 & $26(41.9)$ & $36(44.4)$ & \\
\hline \multicolumn{5}{|l|}{ Age } \\
\hline$<60$ years & 58 & $25(40.3)$ & $33(40.7)$ & \multirow[t]{2}{*}{0.960} \\
\hline$\geq 60$ years & 85 & $37(59.7)$ & $48(59.3)$ & \\
\hline \multicolumn{5}{|l|}{ Tumor size } \\
\hline$<5 \mathrm{~cm}$ & 75 & $29(46.8)$ & $46(56.8)$ & \multirow[t]{2}{*}{0.235} \\
\hline$\geq 5 \mathrm{~cm}$ & 68 & $33(53.2)$ & $35(43.2)$ & \\
\hline \multicolumn{5}{|l|}{ Histology } \\
\hline WD+MD & 122 & $54(87.1)$ & $68(84.0)$ & \multirow[t]{2}{*}{0.598} \\
\hline PD & 21 & $8(12.9)$ & $13(16.0)$ & \\
\hline \multicolumn{5}{|l|}{ T status } \\
\hline $\mathrm{T} 1+\mathrm{T} 2$ & 20 & $6(9.7)$ & $14(17.3)$ & \multirow[t]{2}{*}{0.194} \\
\hline $\mathrm{T} 3+\mathrm{T} 4$ & 123 & $56(60.3)$ & $67(82.7)$ & \\
\hline \multicolumn{5}{|l|}{$\mathrm{N}$ status } \\
\hline N1 & 98 & $40(64.5)$ & $58(71.6)$ & \multirow[t]{2}{*}{0.366} \\
\hline $\mathrm{N} 2$ & 45 & $22(35.5)$ & $23(28.4)$ & \\
\hline \multicolumn{5}{|c|}{ Vascular invasion } \\
\hline No & 93 & $39(62.9)$ & $54(66.7)$ & \multirow[t]{2}{*}{0.640} \\
\hline Yes & 50 & $23(37.1)$ & $27(33.3)$ & \\
\hline \multicolumn{5}{|c|}{ Perineural invasion } \\
\hline No & 100 & $42(67.7)$ & $58(71.6)$ & \multirow[t]{2}{*}{0.618} \\
\hline Yes & 43 & $20(32.3)$ & $23(28.4)$ & \\
\hline \multicolumn{5}{|c|}{ Pre-op CEA, ng/ml } \\
\hline$<5$ & 84 & $35(56.5)$ & $49(60.5)$ & \multirow[t]{2}{*}{0.627} \\
\hline$\geq 5$ & 59 & $27(43.5)$ & $32(39.5)$ & \\
\hline \multicolumn{5}{|c|}{ Post-op CEA, ng/ml } \\
\hline$<5$ & 119 & $53(85.5)$ & $66(81.5)$ & \multirow[t]{2}{*}{0.526} \\
\hline$\geq 5$ & 24 & $9(14.5)$ & $15(18.5)$ & \\
\hline \multicolumn{5}{|l|}{ Recurrence } \\
\hline No & 102 & $38(61.3)$ & $64(79.0)$ & \multirow[t]{2}{*}{0.020} \\
\hline Yes & 41 & $24(38.7)$ & $17(21.0)$ & \\
\hline \multicolumn{5}{|l|}{ Mortality } \\
\hline No & 121 & $45(72.6)$ & $76(93.8)$ & \multirow[t]{2}{*}{$<0.001$} \\
\hline Yes & 22 & $17(27.4)$ & $5(6.2)$ & \\
\hline
\end{tabular}

$\chi^{2}$ tests were used to compare distributions for categorical variables between the FOLFOX4 and FOLFOXU groups, and t-tests were used to compare mean differences between the two groups. WD, well-differentiated; MD, moderately-differentiated; PD, poorly-differentiated; CEA, carcinoembryonic antigen; T, tumor; N, node; FOLFOX4, leucovorin, 5-fluorouracil and oxaliplatin; FOLFOXU, FOLFOX4 plus uracil-tegafur/leucovorin.

impairment. Chemotherapy was discontinued in the case of unacceptable toxicity, disease progression or the refusal of the patient for additional treatment.

Patient follow-up. The clinical records for each patient were retrospectively reviewed. The characteristics of the patients that were recorded included age, gender, the type of chemotherapy administered and any observed recurrence encountered following chemotherapy. The two regimens were continued until one of the following occurred: Recurrence of the disease and/or unacceptable adverse effects, or the patient was lost to follow-up. The median follow-up period was 31 months (range, 7.5-60 months).

Statistical analysis. All data were analyzed using the Statistical Package for the Social Sciences version 17.0 software (SPSS, 
Inc., Chicago, IL, USA). $\chi^{2}$ testing was used to compare distributions for categorical variables, and t-tests were utilized to compare any differences in the continuous variables between FOLFOX4 and FOLFOXU. Using the calculator for survival probability (the Kaplan-Meier method), DFS was defined as the time elapsed between the administration of FOLFOX4 and the date of tumor recurrence, the date of mortality from any cause, or the date at which the last follow-up data was obtained. OS was defined as the time elapsed from the administration of FOLFOX4 until mortality from any cause or until the loss of follow-up date. The DFS and OS values were calculated by the Kaplan-Meier method, and the differences were analyzed by the log-rank test. A logistic regression model was used to identify risk factors for recurrence and mortality. Cox proportional hazard regression model results (for DFS and OS) were applied to estimate the HR of time/probability of mortality/recurrence. A reference group is a group to which another group is compared. $\mathrm{P}<0.05$ was considered to indicate a statistically significant difference.

\section{Results}

The characteristics of these 143 patients with stage III colon cancer are summarized in Table I. All 143 patients were classified into two groups (FOLFOX4 and FOLFOXU), according to the two different regimens of adjuvant chemotherapy. The median age \pm standard deviation was $64.8 \pm 10.9$ years in the FOLFOX4 group (range, 33-81 years) and 63.4 \pm 13.2 years in the FOLFOXU group (range, 20-84 years). A total of 24 patients $(38.7 \%)$ in the FOLFOX4 group who underwent adjuvant FOLFOX4 chemotherapy and 17 patients $(21.0 \%)$ in the FOLFOXU group who underwent sequential FOLFOX4 and oral UFUR/LV chemotherapy had a recurrence of cancer $(P=0.020)$. The recurrence and survival statuses of these patients are summarized in Table I. Among the 62 patients in the FOLFOX4 group, survival was observed in 45 cases (72.6\%). Of the 81 patients in the FOLFOXU group, 76 patients survived (93.8\%; $\mathrm{P}<0.001)$.

As shown in Table II, in seeking to identify the risk factors of recurrence and mortality in the 143 patients with stage III colon cancer using a logistic regression model, a statistically significant association between lower recurrence rate and mortality rate was observed in the FOLFOXU group compared with the FOLFOX4 group (recurrence: OR, 0.312; 95\% CI, 0.131-0.714; $\mathrm{P}=0.008$; mortality: OR, 0.072; 95\% CI, 0.014-0.358; $\mathrm{P}=0.001$ ). In addition, patients with lower post-operative serum carcinoembryonic antigen (CEA) levels $(<5 \mathrm{ng} / \mathrm{ml})$ were prominently associated with lower recurrence and mortality rates (recurrence: OR, 0.134 ; 95\% CI, 0.039-0.462, $\mathrm{P}=0.001$; mortality: OR, 0.053; 95\% CI, 0.007-0.392; $\mathrm{P}=0.004)$.

Cox proportional hazard regression model results were applied to identify the prognostic factors for DFS and OS time (Table III). Through multivariate analyses, it was observed that the FOLFOXU regimen was an independent factor of DFS and OS time (DFS: HR, 0.367; 95\% CI, 0.190-0.709; P=0.003; OS: HR, 0.155; 95\% CI, 0.054-0.450; $\mathrm{P}=0.001)$. Similarly, lower post-operative serum CEA levels $(<5 \mathrm{ng} / \mathrm{ml})$ were another independent factor of DFS and OS time (DFS: HR, 0.279; 95\% CI, 0.115-0.676; P=0.005; OS: HR, 0.173; 95\% CI, 0.050-0.594; $\mathrm{P}=0.005)$.
Fig. 1 shows the OS Kaplan-Meier curves of these two different regimen groups. A statistically significant difference was observed between the OS values of the two groups $(\mathrm{P}=0.001)$. The 5-years OS rate of the FOLFOXU group was $76.9 \%$, which was superior to that of the FOLFOX4 group $(63.8 \%)$. Fig. 2 shows the DFS Kaplan-Meier curves of the two regimen groups. Similarly, a statistically significant difference was observed between the DFS values of the two groups $(\mathrm{P}=0.003)$. The 3-year DFS rate of the FOLFOXU group was $74.3 \%$, which was significantly better compared with that of the FOLFOX4 group (59.9\%). In terms of efficacy, these results showed that FOLFOX4 and subsequent oral UFUR chemotherapy was better than the FOLFOX4 regimen alone.

The rates of various toxicities in the two groups were similar (all $\mathrm{P}>0.05$; Table IV). In terms of grade 3 or 4 events, $57.4 \%$ $(39 / 68)$ of events among the FOLFOXU group patients vs. $53.1 \%(26 / 49)$ of events among the FOLFOX4 groups patients were non-hematological toxicities. The most frequently observed severe non-hematological toxicities were fatigue and diarrhea. In each group, $9.8 \%$ of the patients experienced grade 3 or 4 fatigue during therapy. In the FOLFOXU group, $7.4 \%$ of the patients had grade 3 diarrhea, compared with $4.8 \%$ in the FOLFOX4 group $(\mathrm{P}=0.913)$. A total of 12 of $62(19.3 \%)$ patients in the FOLFOX4 group and 14 of 81 (17.3\%) patients in the FOLFOXU group had elevated liver function. In total, 11 FOLFOX4 patients (17.7\%) and 15 FOLFOXU patients (18.5\%) experienced peripheral sensory neuropathy (grade 3 in 1 FOLFOX4 patient and in 2 FOLFOXU patients) $(\mathrm{P}=0.931)$. The grade $3 / 4$ hematological toxicities, which included neutropenia in $17 / 10(21 \% / 12.3 \%)$ patients in the FOLFOXU group and $13 / 8(21 \% / 12.9 \%)$ patients in the FOLFOX4 group, were comparable between the two groups $(\mathrm{P}=0.940)$.

\section{Discussion}

The recent introduction of drugs, including oxaliplatin, oral capecitabine and UFUR, has increased the treatment options available for these patients $(22,26,28,31)$. One study found that the 3 -year DFS rate was significantly improved in patients who had undergone resection with curative intent for stage II or III colon cancer and received bolus plus continuous-infusion 5-FU plus LV (LV5FU2), with the addition of oxaliplatin (FOLFOX4) (26). In general, adjuvant chemotherapy should be routinely offered to medically fit patients with stage III colon cancer.

In the present retrospective study, patients were enrolled for FOLFOXU subsequent to receiving detailed information regarding the advantages and disadvantages. The present study has shown that the recurrence rates and mortality rates for the FOLFOX4 and FOLFOXU groups were significantly different. Among the patients who received FOLFOX4 chemotherapy without subsequent oral UFUR/LV chemotherapy, 24 patients $(38.7 \%)$ had tumor recurrence and 45 patients $(72.6 \%)$ were alive; whereas in the FOLFOXU group, 64 patients $(79 \%)$ experienced no recurrence and 76 out of $81(93.8 \%)$ patients were alive, both of which represent considerably improved clinical outcomes. Furthermore, the sequential FOLFOX4 and oral UFUR/LV adjuvant chemotherapy resulted in superior DFS and OS rates when compared with FOLFOX4 adjuvant chemotherapy alone, and the present DFS and OS of FOLFOX4 groups were compatible with the results of a previous study 
Table II. Risk factors of recurrence and mortality in 143 stage III colon cancer patients as determined by logistic regression model.

\begin{tabular}{|c|c|c|c|c|}
\hline \multirow[b]{2}{*}{ Factor } & \multicolumn{2}{|c|}{ Recurrence } & \multicolumn{2}{|c|}{ Mortality } \\
\hline & OR $(95 \% \mathrm{CI})$ & P-value & OR $(95 \% \mathrm{CI})$ & P-value \\
\hline \multicolumn{5}{|l|}{ CT formula } \\
\hline \multicolumn{5}{|c|}{ FOLFOX4 (Ref. group) } \\
\hline FOLFOXU & $0.312(0.131-0.741)$ & 0.008 & $0.072(0.014-0.358)$ & 0.001 \\
\hline \multicolumn{5}{|l|}{ Sex } \\
\hline \multicolumn{5}{|c|}{ Male (Ref. group) } \\
\hline Female & $0.725(0.315-1.668)$ & 0.450 & $0.932(0.286-3.034)$ & 0.907 \\
\hline \multicolumn{5}{|l|}{ Age } \\
\hline \multicolumn{5}{|c|}{$<60$ years (Ref. group) } \\
\hline$\geq 60$ years & $1.140(0.492-2.643)$ & 0.760 & $1.536(0.469-5.036)$ & 0.478 \\
\hline \multicolumn{5}{|l|}{ Tumor size } \\
\hline \multicolumn{5}{|c|}{$<5$ cm (Ref. group) } \\
\hline$\geq 5 \mathrm{~cm}$ & $1.239(0.506-3.033)$ & 0.639 & $2.732(0.756-9.870)$ & 0.125 \\
\hline \multicolumn{5}{|l|}{ Histology } \\
\hline \multicolumn{5}{|c|}{ PD (Ref. group) } \\
\hline WD+MD & $0.469(0.142-1.546)$ & 0.213 & $0.179(0.031-1.029)$ & 0.054 \\
\hline \multicolumn{5}{|l|}{ T status } \\
\hline \multicolumn{5}{|c|}{ T3+T4 (Ref. group) } \\
\hline $\mathrm{T} 1+\mathrm{T} 2$ & $0.660(0.174-2.497)$ & 0.540 & $0.622(0.073-5.266)$ & 0.663 \\
\hline \multicolumn{5}{|l|}{$\mathrm{N}$ status } \\
\hline \multicolumn{5}{|c|}{ N2 (Ref. group) } \\
\hline $\mathrm{N} 1$ & $1.574(0.600-4.131)$ & 0.357 & $0.727(0.224-2.356)$ & 0.595 \\
\hline \multicolumn{5}{|c|}{ Vascular invasion } \\
\hline \multicolumn{5}{|c|}{ Yes (Ref. group) } \\
\hline No & $0.796(0.318-1.994)$ & 0.627 & $0.620(0.184-2.090)$ & 0.441 \\
\hline \multicolumn{5}{|c|}{ Perineural invasion } \\
\hline \multicolumn{5}{|c|}{ Yes (Ref. group) } \\
\hline No & $0.604(0.241-1.517)$ & 0.284 & $0.357(0.096-1.330)$ & 0.125 \\
\hline \multicolumn{5}{|c|}{$\begin{array}{l}\text { Pre-op CEA, ng/ml } \\
\geq 5 \text { (Ref. group) }\end{array}$} \\
\hline$<5$ & $1.020(0.380-2.736)$ & 0.968 & $1.580(0.351-7.113)$ & 0.552 \\
\hline \multicolumn{5}{|c|}{$\begin{array}{l}\text { Post-op CEA, ng/ml } \\
\geq 5 \text { (Ref. group) }\end{array}$} \\
\hline$<5$ & $0.134(0.039-0.462)$ & 0.001 & $0.053(0.007-0.392)$ & 0.004 \\
\hline
\end{tabular}

WD, well-differentiated; MD, moderately-differentiated; PD, poorly-differentiated; Ref. group, reference group to which another group is compared; CEA, carcinoembryonic antigen; T, tumor; N, node; CI, confidence interval; OR, odds ratio; FOLFOX4, leucovorin, 5-fluorouracil and oxaliplatin; FOLFOXU, FOLFOX4 plus uracil-tegafur/leucovorin.

from Western countries (26). Despite the finding that patients treated with FOLFOXU chemotherapy experienced somewhat increased gastrointestinal toxicity, including diarrhea, stomatitis and vomiting, the differences in such toxicities were not statistically significant and they were well tolerated in the two groups. In addition, the beneficial prognostic role of sequential FOLFOX4 and oral UFUR/LV adjuvant chemotherapy with the 1-year maintenance therapy remains a crucial issue in clinical practice, since $\sim 50 \%$ of recurrence or metastasis occurred within 1 year of radical resection.
The mean OS time of the patients in the FOLFOXU group with a high postoperative CEA level was 64.28 months, which was superior compared with patients in the FOLFOX4 group with a high postoperative CEA level (26.76 months). A statistically significant difference was observed between the OS values of the two groups $(\mathrm{P}=0.002)$. The average DFS time of the patients in the FOLFOXU group with high postoperative CEA level was 41.54 months, which was superior compared with patients in the FOLFOX4 group with high postoperative CEA level (19.47 months). A borderline significant difference 


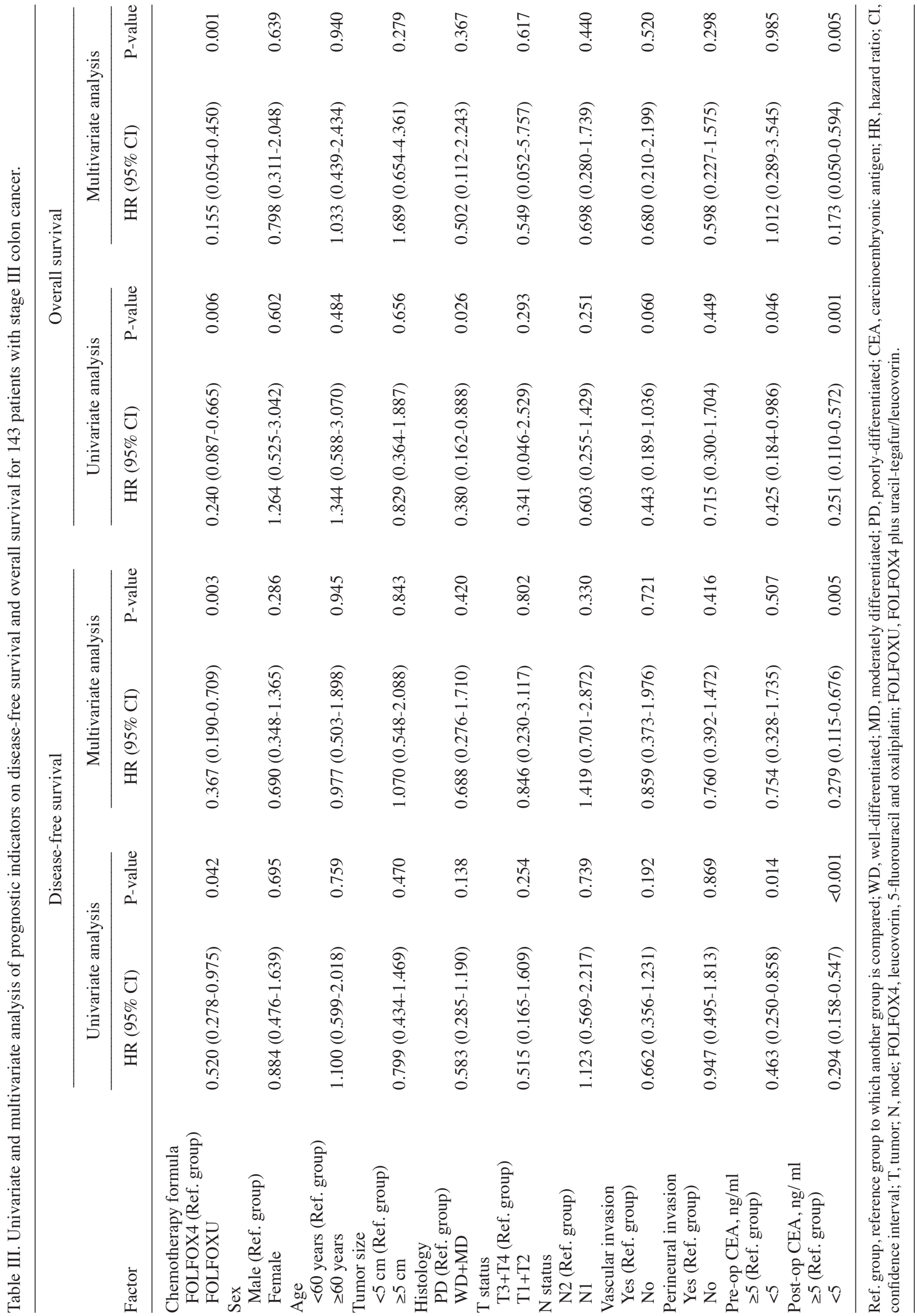


Table IV. Common toxicities of the FOLFOX4 group and FOLFOXU group regimens in 143 patients with stage III colon cancer.

FOLFOX $4, \mathrm{n}(\%)(\mathrm{n}=62)$

FOLFOXU, n $(\%)(\mathrm{n}=81)$

Event

Grade 1 Grade 2 Grade 3 Grade 4 Grade 1 Grade 2 Grade 3 Grade 4 P-value

\begin{tabular}{|c|c|c|c|c|c|c|c|c|c|}
\hline Total events & 156 & 92 & 39 & 10 & 212 & 125 & 56 & 12 & 0.985 \\
\hline Nausea & $24(38.7)$ & $8(12.9)$ & $2(3.2)$ & $0(0)$ & $33(40.7)$ & $11(13.6)$ & $3(3.7)$ & $0(0)$ & 0.996 \\
\hline Vomiting & $11(17.7)$ & $8(12.9)$ & $2(3.2)$ & $0(0)$ & $16(19.8)$ & $11(13.6)$ & $3(3.7)$ & $0(0)$ & 0.994 \\
\hline Anorexia & $11(17.7)$ & $6(9.7)$ & $1(1.6)$ & $0(0)$ & $15(18.5)$ & $8(9.9)$ & $2(2.5)$ & $0(0)$ & 0.952 \\
\hline Stomatitis & $11(17.7)$ & $7(11.3)$ & $1(1.6)$ & $0(0)$ & $15(18.5)$ & $10(12.3)$ & $2(2.5)$ & $0(0)$ & 0.956 \\
\hline Diarrhea & $18(29)$ & $9(14.5)$ & $3(4.8)$ & $0(0)$ & $26(32.1)$ & $14(17.3)$ & $6(7.4)$ & $0(0)$ & 0.913 \\
\hline Abdominal pain & $7(11.3)$ & $6(9.7)$ & $3(4.8)$ & $0(0)$ & $10(12.3)$ & $9(11.1)$ & $4(4.9)$ & $0(0)$ & 0.992 \\
\hline Constipation & $11(17.7)$ & $4(6.5)$ & $1(1.6)$ & $0(0)$ & $14(17.3)$ & $5(6.2)$ & $1(1.2)$ & $0(0)$ & 0.987 \\
\hline Hand-foot syndrome & $3(4.8)$ & $1(1.6)$ & $1(1.6)$ & $0(0)$ & $3(3.7)$ & $1(1.2)$ & $1(1.2)$ & $0(0)$ & 1.000 \\
\hline Pyrexia & $10(16.1)$ & $5(8.2)$ & $1(1.6)$ & $0(0)$ & $14(17.3)$ & $6(7.4)$ & $1(1.2)$ & $0(0)$ & 0.959 \\
\hline Paresthesia & $14(22.6)$ & $4(6.5)$ & $2(3.2)$ & $0(0)$ & $18(22.2)$ & $5(6.2)$ & $3(3.7)$ & $0(0)$ & 0.986 \\
\hline Asthenia & $4(6.5)$ & $4(6.5)$ & $2(3.2)$ & $0(0)$ & $6(7.4)$ & $5(6.2)$ & $3(3.7)$ & $0(0)$ & 0.977 \\
\hline Peripheral sensory neuropathy & $8(12.9)$ & $2(3.2)$ & $1(1.6)$ & $0(0)$ & $10(12.3)$ & $3(3.7)$ & $2(2.5)$ & $0(0)$ & 0.931 \\
\hline Fatigue & $11(17.7)$ & $10(16.1)$ & $5(8.2)$ & $1(1.6)$ & $15(18.5)$ & $14(17.3)$ & $7(8.6)$ & $1(1.2)$ & 0.997 \\
\hline Elevated liver function & $9(14.5)$ & $3(4.8)$ & $0(0)$ & $0(0)$ & $12(14.8)$ & $2(2.5)$ & $0(0)$ & $0(0)$ & 0.635 \\
\hline Neutropenia & $2(3.2)$ & $8(12.9)$ & $13(21.0)$ & $8(12.9)$ & $3(3.7)$ & $11(13.6)$ & $17(21.0)$ & $10(12.3)$ & 0.982 \\
\hline Thrombocytopenia & $2(3.2)$ & $7(11.3)$ & $1(1.6)$ & $1(1.6)$ & $2(2.5)$ & $10(12.3)$ & $1(1.2)$ & $1(1.2)$ & 0.918 \\
\hline
\end{tabular}

FOLFOX4, leucovorin, 5-fluorouracil and oxaliplatin; FOLFOXU, FOLFOX4 plus uracil-tegafur/leucovorin.

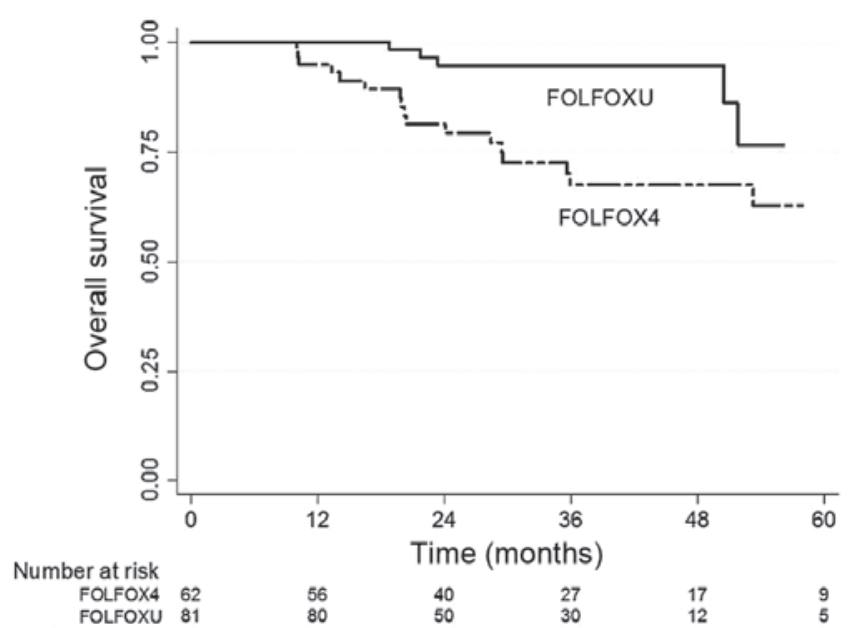

Figure 1. The overall survival rate of patients with stage III colon cancer treated with two different regimens. The overall survival rate of patients with stage III colon cancer treated with FOLFOX4 chemotherapy vs. that of patients treated with the sequential FOLFOX4 and oral FOLFOXU chemotherapy regimens. The overall survival rate was significantly different between the two groups (P=0.001). FOLFOX4, leucovorin, 5-fluorouracil and oxaliplatin; FOLFOXU, FOLFOX4 plus uracil-tegafur/leucovorin.

was observed between the DFS values of the two groups $(\mathrm{P}=0.056)$. Our future prospective study will investigate the benefit of FOLFOXU regimen in the patients with stage III colon cancer with high postoperative CEA level.

The major limitation of the present study was that the comparison of the FOLFOX4 adjuvant chemotherapy alone vs. the sequential FOLFOX4 and oral UFUR/LV adjuvant chemotherapy was not based on a prospective randomized design, but

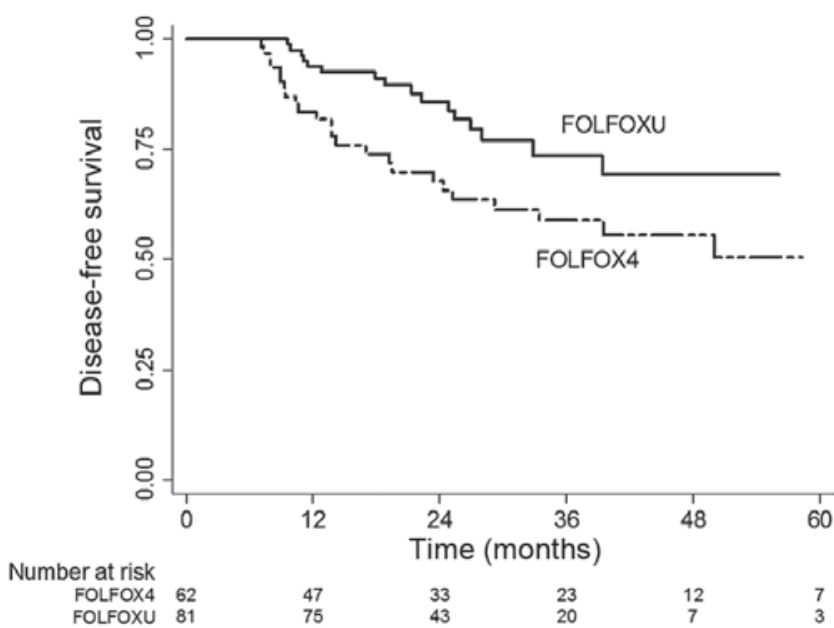

Figure 2. The disease-free survival rate of patients with stage III colon cancer treated with two different regimens. The disease-free survival rate of patients with stage III colon cancer treated with FOLFOX4 chemotherapy vs. that of patients treated with the sequential FOLFOX4 and oral FOLFOXU chemotherapy regimens. The disease-free survival rate was significantly different between the two groups $(\mathrm{P}=0.003)$. FOLFOX4, leucovorin, 5-fluorouracil and oxaliplatin; FOLFOXU, FOLFOX4 plus uracil-tegafur/leucovorin.

was accomplished via a retrospective review. Another limitation was that only the 5-year OS rates were available, due to the limited follow-up period. The validation of these findings with larger sample sizes with a longer follow-up period from multicenter sources would be crucial in our future prospective study. A future prospective, randomized study may investigate the potential benefit of FOLFOXU regimen in patients with stage III colon cancer to verify the current retrospective study. 
In conclusion, patients with stage III colon cancer may be more prone to benefit from sequential FOLFOX4 and oral UFUR/LV adjuvant chemotherapy than from the adjuvant FOLFOX4 chemotherapy alone; however, a prospective, randomized clinical trial is required to confirm the findings of the current retrospective study.

\section{Acknowledgements}

The present study was supported by grants from the Excellence for Cancer Research Center Grant through funding by the Ministry of Science and Technology (grant no. MOST105-2325-B-037-001), the Ministry of Health and Welfare (grant no. MOHW106-TDU-B-212-144007; Health and Welfare Surcharge of Tobacco Products, Taiwan, R.O.C.), the Kaohsiung Medical University Hospital (grant nos. KMUH104-4M46, KMUH105-5R26, KMUHS10601, KMUHS10608 and KMUHA10664). In addition, the present study was supported by Kaohsiung Medical University 'Aim for the Top 500 University Grant' (grant nos. KMU-TP105C01, KMU-TP105C02 and KMU-TP105C11) and 'Aim for the top University Grant' [grant nos. KMU-TP105A14 and SH000113 (Give2Asia)] and the Grant of Biosignature in Colorectal Cancers, Academia Sinica, Taiwan, R.O.C. (grant no. T106-002).

\section{References}

1. Ferlay J, Soerjomataram I, Ervik M, Dikshit R, Eser S, Mathers C Rebelo M, Parkin DM, Forman D and Bray F: GLOBOCAN 2012 v1.0, Cancer incidence and mortality worldwide. IARC CancerBase no. 11, Lyon, 2013.

2. Pestana C, Reitemeier RJ, Moertel CG, Judd ES and Dockerty MB: The natural history of carcinoma of the colon and rectum. Am J Surg 108: 826-829, 1964.

3. Falterman KW, Hill CB, Markey JC, Fox JW and Cohn I Jr: Cancer of the colon, rectum, and anus: A review of 2313 cases. Cancer 34 (Suppl): S951-S959, 1974.

4. Olson RM, Perencevich NP, Malcolm AW, Chaffey JT and Wilson RE: Patterns of recurrence following curative resection of adenocarcinoma of the colon and rectum. Cancer 45: 2969-2974, 1980.

5. Moertel CG, Fleming TR, Macdonald JS, Haller DG, Laurie JA, Goodman PJ, Ungerleider JS, Emerson WA, Tormey DC, Glick JH, et al: Levamisole and fluorouracil for adjuvant therapy of resected colon carcinoma. N Engl J Med 322: 352-358, 1990.

6. Ha GS, Kim YW, Choi EH and Kim IY: Factors associated with the lack of adjuvant chemotherapy following curative surgery for stage II and III colon cancer: A Korean National Cohort Study. Anticancer Res 37: 915-922, 2017.

7. Bos AC, van Erning FN, van Gestel YR, Creemers GJ, Punt CJ, van Oijen MG and Lemmens VE: Timing of adjuvant chemotherapy and its relation to survival among patients with stage III colon cancer. Eur J Cancer 51: 2553-2561, 2015.

8. No authors listed: Efficacy of adjuvant fluorouracil and folinic acid in colon cancer. International Multicentre Pooled Analysis of Colon Cancer Trials (IMPACT) investigators. Lancet 345: 939-944, 1995.

9. Moertel CG, Fleming TR, Macdonald JS, Haller DG, Laurie JA, Tangen CM, Ungerleider JS, Emerson WA, Tormey DC, Glick JH, et al: Fluorouracil plus levamisole as effective adjuvant therapy after resection of stage III colon carcinoma: A final report. Ann Intern Med 122: 321-326, 1995.

10. O'Connell MJ,Laurie JA, Kahn M, Fitzgibbons RJ Jr, Erlichman C, Shepherd L, Moertel CG, Kocha WI, Pazdur R, Wieand HS, et al: Prospectively randomized trial of postoperative adjuvant chemotherapy in patients with high-risk colon cancer. J Clin Oncol 16 : 295-300, 1998.

11. Wolmark N, Rockette H, Fisher B, Wickerham DL, Redmond C, Fisher ER, Jones J, Mamounas EP, Ore L, Petrelli NJ, et al: The benefit of leucovorin-modulated fluorouracil as postoperative adjuvant therapy for primary colon cancer: Results from National Surgical Adjuvant Breast and Bowel Project protocol C-03. J Clin Oncol 11: 1879-1887, 1993.
12. NIH consensus conference. Adjuvant therapy for patients with colon and rectal cancer. JAMA 264: 1444-1450, 1990.

13. Peters GJ, van der Wilt CL, van Groeningen CJ, Smid K, Meijer S and Pinedo HM: Thymidylate synthase inhibition after administration of fluorouracil with or without leucovorin in colon cancer patients: Implications for treatment with fluorouracil. J Clin Oncol 12: 2035-2042, 1994.

14. Kelsen DP, Saltz L, Cohen AM, Yao TJ, Enker W, Tong W, Tao Y and Bertino JR: A phase I trial of immediate postoperative intraperitoneal floxuridine and leucovorin plus systemic 5-fluorouracil and levamisole after resection of high risk colon cancer. Cancer 74: 2224-2233, 1994.

15. Department of Health, the Executive Yuan: Cancer registry annual report. Taiwan, Republic of China, 2012.

16. International Union Against Cancer: TNM classification of malignant tumors. Sobin LH and Wittekind C (eds). 6th edition. Wiley-Liss Inc., New York, 2002.

17. Fleshman JW, Nelson H, Peters WR, Kim HC, Larach S, Boorse RR, Ambroze W, Leggett P, Bleday R, Stryker S, et al: Early results of laparoscopic surgery for colorectal cancer. Retrospective analysis of 372 patients treated by Clinical Outcomes of Surgical Therapy (COST) study group. Dis Colon Rectum 39 (10 Suppl): S53-S58, 1996.

18. Franklin ME Jr, Rosenthal D, Abrego-Medina D, Dorman JP, Glass JL, Norem R and Diaz A: Prospective comparison of open vs. laparoscopic colon surgery for carcinoma. Five-year results. Dis Colon Rectum 39 (10 Suppl): S35-S46, 1996.

19. Bokey EL, Moore JW, Chapuis PH and Newland RC: Morbidity and mortality following laparoscopic-assisted right hemicolectomy for cancer. Dis Colon Rectum 39 (10 Suppl): S24-S28, 1996.

20. Schwenk W, Bohm B and Müller JM: Postoperative pain and fatigue after laparoscopic or conventional colorectal resections. A prospective randomized trial. Surg Endosc 12: 1131-1136, 1998.

21. André T, Boni C, Mounedji-Boudiaf L, Navarro M, Tabernero J, Hickish T, Topham C, Zaninelli M, Clingan P, Bridgewater J, et al: Oxaliplatin, fluorouracil, and leucovorin as adjuvant treatment for colon cancer. N Engl J Med 350: 2343-2351, 2004.

22. Twelves C, Wong A, Nowacki MP, Abt M, Burris H III, Carrato A, Cassidy J, Cervantes A, Fagerberg J, Georgoulias V, et al: Capecitabine as adjuvant treatment for stage III colon cancer. N Engl J Med 352: 2696-2704, 2005.

23. Haller DG, Catalano PJ, Macdonald JS, O'Rourke MA, Frontiera MS, Jackson DV and Mayer RJ: Phase III study of fluorouracil, leucovorin, and levamisole in high-risk stage II and III colon cancer: Final report of Intergroup 0089. J Clin Oncol 23: 8671-8678, 2005.

24. Panettiere FJ, Goodman PJ, Costanzi JJ, Cruz AB Jr, Vaitkevicius VK, McCracken JD, Brownlee RW, Laufman L, Stephens RL, Bonnet J, et al: Adjuvant therapy in large bowel adenocarcinoma: Long-term results of a Southwest Oncology Group Study. J Clin Oncol 6: 947-954, 1988.

25. Andre T, Boni C, Mounedji-Boudiaf L, Navarro M, Tabernero J, Hickish T, Topham C, Zaninelli M, Clingan P, Bridgewater J, et al: Oxaliplatin, fluorouracil, and leucovorin as adjuvant treatment for colon cancer. N Engl J Med 350: 2343-2351, 2004.

26. André T, Boni C, Navarro M, Tabernero J, Hickish T, Topham C, Bonetti A, Clingan P, Bridgewater J, Rivera F and de Gramont A: Improved overall survival with oxaliplatin, fluorouracil, and leucovorin as adjuvant treatment in stage II or III colon cancer in the MOSAIC trial. J Clin Oncol 27: 3109-3116, 2009.

27. Kurihara M, Uchida J, Fujioka A, Kato T, Ohshimo H, Abe M, Takeda S and Fukushima M: Effect of combination therapy with UFT plus cisplatin (UFTP) on the survival of mice in the experimental model for wide-spread metastasis in the peritoneal cavity of gastrointestinal cancer using colon 26 PMF-15 cells. Anticancer Res 17: 2217-2220, 1997.

28. Smith RE, Lembersky BC, Wieand HS, Colangelo L and Mamounas EP: UFT/leucovorin vs 5-FU/leucovorin in colon cancer. Oncology (Williston Park) 14 (10 Suppl 9): S24-S27, 2000.

29. Pazdur R, Lassere Y, Rhodes V, Ajani JA, Sugarman SM, Patt YZ, Jones DV Jr, Markowitz AB, Abbruzzese JL, Bready B, et al: Phase II trial of uracil and tegafur plus oral leucovorin: An effective oral regimen in the treatment of metastatic colorectal carcinoma. J Clin Oncol 12: 2296-2300, 1994.

30. Saltz LB, Leichman CG, Young CW, Muggia FM, Conti JA, Spiess T, Jeffers S and Leichman LP: A fixed-ratio combination of uracil and Ftorafur (UFT) with low dose leucovorin. An active oral regimen for advanced colorectal cancer. Cancer 75: 782-785, 1995. 
31. Meropol NJ, Rustum YM, Petrelli NJ, Rodriguez-Bigas M, Frank C, Ho DH, Kurowski M and Creaven PJ: A phase I and pharmacokinetic study of oral uracil, ftorafur, and leucovorin in patients with advanced cancer. Cancer Chemother Pharmacol 37: 581-586, 1996

32. Mukai M, Moriya H, Himeno S, Oida Y, mukohyama S, Nishi T, Nakasaki H, Satoh S and Makuuchi H: Efficacy of oral UFT plus leucovorin therapy for colon cancer with ovarian and multiple liver metastases: Report of two cases. Oncol Rep 8: 1079-1083, 2001.
33. West HJ and Jin JO: JAMA oncology patient page. Performance status in patients with cancer. JAMA Oncol 1: 998, 2015.

34. U.S. Department of Health and Human Services, National Institutes of Health, National Cancer Institute: Common terminology criteria for adverse events (CTCAE), version 4.0, 2009. 